\title{
NUTRIÇÃO DE MUDAS DE AÇAIZEIRO SOB RELAÇÕES CÁLCIO:POTÁSSIO:SÓDIO EM SOLUÇÃO NUTRITIVA ${ }^{1}$
}

\author{
Nutrition of açai seedlings (Euterpe oleracea Mart.) under different \\ ratios of calcium:potassium: sodium in nutrient solution
}

\author{
Humberto Umbelino de Sousa ${ }^{2}$, José Darlan Ramos ${ }^{3}$, Janice Guedes de Carvalho ${ }^{4}$, Ester Alice Ferreira ${ }^{5}$
}

\begin{abstract}
RESUMO
Objetivando-se estudar diferentes relações entre os cátions cálcio, potássio e sódio na produção de matéria seca e acúmulo de macronutrientes em mudas de açaizeiro (Euterpe oleracea Mart.), realizou-se um experimento em casa-de-vegetação no Departamento de Ciência do Solo da UFLA. Utilizou-se o delineamento estatístico em blocos casualisados com nove tratamentos em quatro repetições. Os tratamentos foram constituídos por nove relações cálcio: potássio: sódio (4:2:1, 3:3:1, 2:4:1, 1:5:1, 5:1:1, 4:1:2, 6:0:1; 0:6:1, e 4:2:0) em solução nutritiva. A unidade experimental constituiu-se de um vaso com capacidade para três litros de solução, contendo duas plantas. Avaliaram-se as seguintes características: produção de matéria seca e o acúmulo dos macronutrientes fósforo, cálcio, potássio, magnésio e enxofre na matéria seca da planta. A relação cálcio:potássio:sódio influenciou todas as características avaliadas; as soluções contendo cálcio, potássio e sódio nas relações 4:2:1 e 3:3:1 resultaram no desenvolvimento de mudas com maior produção de matéria seca e maior acúmulo de nutrientes.
\end{abstract}

Termos para Indexação: Açaí, Euterpe oleracea, propagação.

\section{ABSTRACT}

Aiming to evaluate the effects of different ratios of calcium, potassium and sodium cations on the mineral nutrition of açai seedlings (Euterpe oleracea Mart.), a greenhouse experiment was carried out in the Soil Science Department at the Federal University of Lavras-UFLA. The randomized block design, with nine treatments and four replications, was used. The treatments were nine ratios of calcium, potassium and sodium $(4: 2: 1,3: 3: 1,2: 4: 1,1: 5: 1,5: 1: 1,4: 1: 2,6: 0: 1 ; 0: 6: 1$, e 4:2:0) in the nutrient solution. The experimental unit was a plastic pot with three liters of solution, containing two plants. The total dry matter and nutrient accumulation were evaluated. The relationship calcium:potassium:sodium influenced all the appraised characteristics, and the solutions containing calcium, potassium and sodium in the ratios 4:2:1 and 3:3:1 resulted in seedlings development with larger production of dry matter and larger accumulation of nutrients.

Index Terms: Açaí, Euterpe oleracea, propagation.

(Recebido para publicação em 22 de novembro de 2002 e aprovado em 26 de junho de 2003)

\section{INTRODUÇÃO}

O açaizeiro (Euterpe oleracea Mart.) é uma importante frutífera da Amazônia, cujos frutos são extraídos e utilizados na produção de sucos, sorvetes, cremes, picolés, licores, além de outros usos. Constitui-se na principal fonte de proteínas, energia e sais minerais para os povos da floresta, sendo considerado como o segundo produto agrícola mais consumido pela população da Região Amazônica, apenas superado pela farinha de mandioca (OLIVEIRA et al., 2000).
Embora se constitua em fonte básica de alimento, raros são os estudos que abordam a nutrição mineral do açaizeiro. Deve-se ressaltar que a relação existente entre um nutriente e os demais poderá influenciar sua absorção e dificultar ou impedir a absorção dos outros nutrientes. $\mathrm{O}$ crescimento adequado das plantas é alcançado quando são proporcionadas as melhores condições para a absorção, distribuição e observadas as devidas proporções entre os nutrientes. Quantidades excessivas podem causar antagonismo entre eles, ocasionando perdas consideráveis na produção das culturas (MALAVOLTA, 1976).

\footnotetext{
1. Parte da tese de Doutorado apresentada a Universidade Federal de Lavras/UFLA - Caixa Postal 37 - 37200-000 - Lavras, MG, pelo primeiro autor.

2. Pesquisador III Embrapa Meio-Norte. Caixa Postal 341, 64200-970 - Parnaíba, PI. humberto@cpamn.embrapa.br

3. Professor Adjunto, Departamento de Agricultura da UFLA darlan@ufla.br

4. Professora Titular, Departamento de Ciência do Solo da UFLA

5. Doutoranda em Fitotecnica/UFLA. ester@ufla.br
} 
A disponibilidade de um determinado nutriente para as plantas é mais bem prevista pela relação entre eles no meio do que pela simples concentração. Desse modo, relações adequadas dos nutrientes no meio de cultivo podem permitir melhor balanço dos nutrientes na planta, facilitando o estudo de diagnose (GUNES et al., 1998).

As relações catiônicas nas plantas são uma função linear da relação correspondente aos nutrientes no meio (MORTVEDET e KHASAWNEH, 1986). Porém, essa relação é limitada pelas interações entre íons durante o processo de absorção e distribuição na planta, tendo em vista que as raízes regulam a absorção de nutrientes pela planta, mas apenas dentro de uma faixa limitada de concentrações dos nutrientes no meio, sendo de vital importância definir as relações catiônicas que propiciem as melhores condições para o desenvolvimento de cada espécie vegetal (SONNEVELD e VOOGT, 1985).

Entre os nutrientes catiônicos, o potássio e o cálcio interagem entre si, de forma que pode ocorrer antagonismo. No entanto, o cálcio em baixas concentrações exerce um efeito estimulante na absorção de potássio, ao passo que quando em altas concentrações, ocorre redução na absorção de potássio pelas plantas (MALAVOLTA, 1976; ASSIS, 1995). Efeito semelhante é observado com a concentração do potássio, em que baixas concentrações de potássio tornam máxima a absorção de cálcio, ao passo que em altas concentrações ocorre redução na absorção do cálcio (VENTURA, 1987; KURIHARA, 1991).

O sódio tem sido considerado por muitos autores como um elemento útil para as espécies pertencentes à família Arecaceae, uma vez que tem estimulado o crescimento e proporcionado aumentos de produção (BONNEAU et al., 1993; MAGAT et al., 1993).

Entre os trabalhos que abordam a nutrição mineral das palmáceas, destaca-se o trabalho pioneiro realizado por Dufour et al. (1978), no qual foi estabelecida uma solução nutritiva básica para o dendezeiro. Com base nesse trabalho, Assis (1995) avaliou diferentes relações entre os nutrientes cálcio, potássio e magnésio, não encontrando efeito dessas relações sobre o crescimento do dendezeiro, embora o equilíbrio nutricional das plantas esteja relacionado com o nível de disponibilidade dos cátions $\mathrm{K}, \mathrm{Ca}$ e $\mathrm{Mg}$ no meio de crescimento (MENGEL e KIRKBY, 1987; DALIPARTHY et al., 1994).
Para o cultivo do açaizeiro, não existe informação referente à adequada relação entre cálcio, potássio e sódio, de forma que propicie suprimento balanceado de nutrientes e, em decorrência possibilite o maior crescimento da planta.

Dessa forma, com este trabalho teve-se como objetivo avaliar diferentes relações entre os cátions cálcio, potássio e sódio sobre a produção de matéria seca e o acúmulo de macronutrientes em mudas de açaizeiro em solução nutritiva.

\section{MATERIAL E MÉTODOS}

O experimento foi realizado em casa-devegetação do Departamento de Ciência do Solo da Universidade Federal de Lavras (UFLA), Lavras, MG, durante o período de 09/11/1999 a 04/04/2000.

As sementes do açaizeiro foram colocadas para germinar e quando as plântulas atingiram média de $0,10 \mathrm{~m}$ de altura, foram repicadas para uma bandeja coletiva, com capacidade para 36 litros. Utilizou-se a solução nutritiva $4: 2: 1 \mathrm{mmol} \mathrm{L}^{-1}$ de cálcio, potássio e sódio, respectivamente, estabelecida por Dufour et al. (1978) para o dendezeiro. Nos primeiros 30 dias, as plantas permaneceram na solução nutritiva diluída a $20 \%$ de sua concentração inicial. Após esse período, a solução foi substituída pela solução base diluída a $50 \%$, permanecendo por mais 30 dias. Decorrido esse período, procedeu-se à substituição da solução, empregando-se a soluçãobase a $100 \%$ de sua concentração, com as plantas permanecendo por mais 30 dias. Após esse período, as plantas foram repicadas para os vasos contendo os tratamentos.

Utilizou-se o delineamento estatístico em blocos casualizados, com nove tratamentos e quatro repetições. A parcela experimental foi constituída por um vaso com capacidade para três litros de solução, contendo duas plantas. Os tratamentos foram constituídos por nove relações entre cálcio, potássio e sódio, conforme apresentado na Tabela 1.

O tratamento-testemunha foi a solução-base proposta para o dendezeiro por Dufour et al. (1978), mantendo-se a relação entre cálcio:potássio:sódio de 4:2:1 mmol L $\mathrm{L}^{-1}$, enquanto nos demais tratamentos, alterou-se a relação cálcio:potássio:sódio, mantendo-se o balanço iônico em todas as soluções.

As soluções nutritivas foram substituídas em intervalos de 21 dias durante os primeiros 105 dias pósinstalação e, a partir desse período, foram efetuadas 
substituições com intervalos de 14 dias. O nível da solução foi mantido, diariamente, pela água deionizada, para repor a solução absorvida pelas plantas de cada vaso.

Aos 147 dias após sua instalação, procedeu-se ao corte das plantas na região do coleto, sendo o material separado em parte aérea e raiz. Em seguida, todo o material foi submetido a duas lavagens em água corrente, sendo a primeira em água comum e a segunda em água destilada. Após a lavagem, o material foi colocado para secar em estufa com circulação forçada de ar, sob temperatura de $65^{\circ} \mathrm{C}$, até atingir massa constante, quando se estimou a produção total de matéria seca (ptms). Posteriormente, o material foi moído e encaminhado ao Laboratório de Análise Foliar do Departamento de Química da Universidade Fede- ral de Lavras, para análise e determinação dos nutrientes fósforo, cálcio, potássio, magnésio e enxofre. O acúmulo dos nutrientes foi obtido pela multiplicação da matéria seca produzida por cada parte da planta pela respectiva concentração de cada nutriente. Os dados experimentais foram submetidos à análise de variância, sem haver transformação de dados. Para as características em que houve significância, aplicou-se o teste de Scott-Knott a 5\% de probabilidade.

\section{RESULTADOS E DISCUSSÃO}

Pela análise de variância, observou-se influência dos tratamentos sobre as características avaliadas, conforme apresentado na (Tabela 2).

TABELA 1 - Relação cálcio:potássio:sódio e respectivas concentrações na solução nutritiva.

\begin{tabular}{cccccccccc}
\hline \multirow{2}{*}{ Elemento } & \multicolumn{7}{c}{ Relação cálcio:potássio:sódio $\left(\mathbf{m m o l ~} \mathbf{L}^{-\mathbf{1}}\right)$} \\
\cline { 2 - 10 } & $\mathbf{4 : 2 : 1}$ & $\mathbf{3 : 3 : 1}$ & $\mathbf{2 : 4 : 1}$ & $\mathbf{1 : 5 : 1}$ & $\mathbf{5 : 1 : 1}$ & $\mathbf{4 : 1 : 2}$ & $\mathbf{6 : 0 : 1}$ & $\mathbf{0 : 6 : 1}$ & $\mathbf{4 : 2 : 0}$ \\
\hline $\mathrm{K}^{+}$ & 2 & 3 & 4 & 5 & 1 & 1 & 0 & 6 & 2 \\
$\mathrm{Ca}^{+2}$ & 2 & 1,5 & 1 & 0,5 & 2,5 & 2 & 3 & 0 & 2 \\
$\mathrm{Mg}^{+2}$ & 1,5 & 1,5 & 1,5 & 1,5 & 1,5 & 1,5 & 1,5 & 1,5 & 1,5 \\
$\mathrm{Na}^{+}$ & 1 & 1 & 1 & 1 & 1 & 2 & 1 & 1 & 0 \\
$\mathrm{~N}^{-} \mathrm{NH}_{4}{ }^{+}$ & 2 & 2 & 2 & 2 & 2 & 2 & 2 & 2 & 2 \\
$\mathrm{~N}^{-N^{-}}$ & 8 & 8 & 8 & 8 & 8 & 8 & 8 & 8 & 8 \\
$\mathrm{H}_{2} \mathrm{PO}_{4}^{-}$ & 1 & 1 & 1 & 1 & 1 & 1 & 1 & 1 & 1 \\
$\mathrm{SO}_{4}^{-2}$ & 1 & 1 & 1 & 1 & 1 & 1 & 1 & 1 & 1 \\
$\mathrm{Cl}^{-}$ & 0,5 & 0,5 & 0,5 & 0,5 & 0,5 & 0,5 & 0,5 & 0,5 & 0,5 \\
\hline
\end{tabular}

Ciênc. agrotec., Lavras, v. 28, n. 1, p. 56-62, jan./fev., 2004 
TABELA 2 - Valores médios de produção de matéria seca (ptms) e acúmulo de nutrientes por mudas de açaizeiro cultivadas sob diferentes relações cálcio:potássio:sódio, em solução nutritiva.

\begin{tabular}{ccccccc}
\hline \multirow{2}{*}{$\begin{array}{c}\text { Ca:K:Na } \\
\left(\mathbf{m m o l}_{\mathbf{L}} \mathbf{- 1}\right)\end{array}$} & ptms $\left(\mathbf{g ~ v a s o}^{\mathbf{- 1}}\right)$ & \multicolumn{5}{c}{ Característica* $^{*}$} \\
\cline { 2 - 7 } & & $\mathbf{P}$ & $\mathbf{C a}$ & $\mathbf{K}$ & $\mathbf{M g}$ & $\mathbf{S}$ \\
\hline $4: 2: 1$ & $52,03 \mathrm{a}$ & $0,680 \mathrm{a}$ & $0,530 \mathrm{a}$ & $0,958 \mathrm{a}$ & $0,162 \mathrm{a}$ & $0,214 \mathrm{a}$ \\
$1: 5: 1$ & $49,84 \mathrm{a}$ & $0,649 \mathrm{a}$ & $0,417 \mathrm{~b}$ & $0,908 \mathrm{a}$ & $0,166 \mathrm{a}$ & $0,176 \mathrm{a}$ \\
$3: 3: 1$ & $48,84 \mathrm{a}$ & $0,655 \mathrm{a}$ & $0,490 \mathrm{a}$ & $0,928 \mathrm{a}$ & $0,170 \mathrm{a}$ & $0,181 \mathrm{a}$ \\
$4: 2: 0$ & $47,66 \mathrm{a}$ & $0,595 \mathrm{~b}$ & $0,500 \mathrm{a}$ & $0,953 \mathrm{a}$ & $0,150 \mathrm{~b}$ & $0,182 \mathrm{a}$ \\
$2: 4: 1$ & $47,33 \mathrm{a}$ & $0,602 \mathrm{~b}$ & $0,517 \mathrm{a}$ & $0,800 \mathrm{~b}$ & $0,153 \mathrm{~b}$ & $0,181 \mathrm{a}$ \\
$4: 1: 2$ & $47,22 \mathrm{a}$ & $0,588 \mathrm{~b}$ & $0,519 \mathrm{a}$ & $0,780 \mathrm{~b}$ & $0,140 \mathrm{~b}$ & $0,177 \mathrm{a}$ \\
$6: 0: 1$ & $42,72 \mathrm{~b}$ & $0,495 \mathrm{c}$ & $0,376 \mathrm{~b}$ & $0,109 \mathrm{c}$ & $0,188 \mathrm{a}$ & $0,189 \mathrm{a}$ \\
$5: 1: 1$ & $38,73 \mathrm{~b}$ & $0,490 \mathrm{c}$ & $0,474 \mathrm{a}$ & $0,633 \mathrm{~b}$ & $0,111 \mathrm{c}$ & $0,139 \mathrm{~b}$ \\
$0: 6: 1$ & $34,33 \mathrm{c}$ & $0,417 \mathrm{~d}$ & $0,138 \mathrm{c}$ & $0,687 \mathrm{~b}$ & $0,111 \mathrm{c}$ & $0,109 \mathrm{~b}$ \\
\hline
\end{tabular}

* Médias seguidas pela mesma letra, nas colunas, não diferem estatisticamente entre si pelo teste de ScottKnott a 5\% de probabilidade.

Para a produção de matéria seca, foi constatado menor valor nas plantas submetidas à solução, cuja relação cálcio:potássio:sódio foi $0: 6: 1$, seguida das soluções contendo cálcio:potássio:sódio na relação 5:1:1 e 6:0:1, enquanto os maiores valores foram verificados nas plantas cultivadas nas outras soluções, sem diferença significativa entre elas. A menor produção observada pode ser atribuída à ausência do cálcio nessa solução, em razão de o cálcio atuar tanto no processo de síntese de parede celular, quanto como segundo mensageiro, formando um complexo cálcio-calmodulina, o qual está envolvido na regulação de vários processos metabólicos (TAIZ e ZEIGER, 1991). Além desse motivo, pode ter ocorrido inibição da absorção do potássio nas outras soluções em virtude da alta concentração de cálcio em relação ao potássio, na ordem de 5:1 e 6:0, respectivamente.

Em plantas de seringueira, foi observado que o cálcio promoveu aumentos na produção total de matéria seca até a concentração $50 \mathrm{mg} \mathrm{L}^{-1}$, em solução nutritiva, e a partir daí, ocorreu redução (COSTACURTA et al., 1995). Mudas de pupunheira cultivadas em solução nutritiva contendo cálcio e potássio na relação 3:3 apresentaram maiores valores de matéria seca, enquanto os menores valores foram detectados quando as plantas foram submetidas à solução sem potássio (FERNANDES,
2000). Contudo, Assis (1995) e Pacheco et al. (1999) não constataram efeito da relação cálcio:potássio e da aplicação de doses de cálcio, respectivamente, sobre a produção de matéria seca em mudas de dendezeiro e de pupunheira.

Quanto ao efeito do sódio, observa-se pela Tabela 2 que não houve influência desse elemento sobre a produção de matéria seca. No entanto, em mudas de pupunheira ocorreu redução na matéria seca produzida quando se substituiu parte do potássio pelo sódio (FERNANDES, 2000).

Em relação ao acúmulo de nutrientes, observouse menor acúmulo de fósforo nas plantas cultivadas tanto na ausência do cálcio, relação cálcio:potássio:sódio 0:6:1, quanto na presença de altas concentrações de cálcio, ou seja, relações 5:1:1 e 6:0:1, ao passo que os maiores acúmulos foram obtidos nas plantas cultivadas nas soluções contendo cálcio, potássio e sódio nas relações 4:2:1, 3:3:1 e 1:5:1. A alteração na relação-base entre potássio e sódio reduziu o acúmulo de fósforo, quando comparada à solução-base (Tabela 2). $\mathrm{O}$ menor acúmulo detectado nas plantas cultivadas nessas soluções pode ser atribuído tanto à ausência do cálcio, em virtude de a deficiência desse nutriente deprimir o crescimento do sistema radicular (MARSCHNER, 1997) e, com isso, limitar a absorção e o acúmulo do fósforo, 
quanto às altas concentrações de cálcio, que na ordem de 5 e $6 \mathrm{mmol} \mathrm{L}^{-1}$ podem reduzir a disponibilidade do fósforo em virtude de sua ligação com o cálcio e esse composto apresentar baixa solubilidade (MARSCHNER, 1997). No entanto, efeito semelhante foi detectado em mudas de pupunheira, verificando-se menor absorção total de fósforo quando as plantas foram cultivadas nas soluções cuja relação cálcio:potássio:sódio foi 6:0:1 e 4:2:0 (FERNANDES, 2000), ao passo que não foi observada influência de doses de potássio, cálcio e sódio sobre o teor de fósforo na matéria seca em plantas de gramíneas forrageiras (SILVA et al., 1995).

Com relação ao efeito do sódio, observou-se que quando o sódio foi suprimido da solução, ocorreu redução no acúmulo de fósforo, semelhante ao detectado por Fernandes (2000) em mudas de pupunheira.

Para o cálcio, foi observado que o menor acúmulo ocorreu nas plantas cultivadas na solução em que não houve suprimento de cálcio, ao passo que maiores acúmulos ocorreram nas soluções em que o cálcio foi aplicado, embora havendo diferença significativa entre elas, dependendo da relação com o potássio, independentemente da presença do sódio (Tabela 2). Os menores valores obtidos podem ter sido ocasionados tanto pela ausência do cálcio nessa solução, quanto pela baixa disponibilidade em decorrência da alta concentração de potássio na solução 1:5:1, ou mesmo pela ausência do potássio, na solução contendo apenas cálcio e sódio, ou seja, cálcio:potássio:sódio 6:0:1, visto que a ausência ou baixa disponibilidade de um desses nutrientes reduz a absorção do outro, conforme constatado nas culturas de soja (VENTURA, 1987; KURIHARA, 1991), milho (CARMELO, 1989; RODRIGUES e ROSSIELLO, 1995) e pupunheira (FERNANDES, 2000).

Verificou-se que na solução em que o potássio não foi fornecido, as plantas apresentaram o menor acúmulo desse nutriente, enquanto maiores valores ocorreram nas plantas cultivadas nas soluções contendo cálcio:potássio:sódio nas relações 4:2:1, 3:3:1, 1:5:1 e 4:2:0, sem diferença significativa dentro desse grupo de tratamentos. O menor acúmulo é explicado pela ausência do potássio naquela solução, cuja relação cálcio:potássio:sódio foi 6:0:1, haja vista que nos tratamentos com baixa relação diante da concentração de cálcio (5:1 e 4:1) também resultaram menores acúmulos totais. Os resultados obtidos neste trabalho são semelhantes aos registrados em mudas de pupunheira submetidas a diferentes relações cálcio, potássio e sódio, nos quais menores valores de potássio absorvido foram registrados nas plantas cultivadas na solução cujas relações entre cálcio:potássio:sódio foram 6:0:1, 5:1:1 e 4:1:2, res- pectivamente (FERNANDES, 2000). Contudo, foram constatados incrementos no teor de potássio na matéria seca de espécies forrageiras com aplicação de doses de potássio, independentemente das doses de cálcio e sódio aplicadas (SILVA et al., 1995; RODRIGUES e ROSSIELLO, 1995).

O acúmulo de magnésio também não foi favorecido quando as plantas foram cultivadas nas soluções contendo cálcio:potássio:sódio nas relações 5:1:1 e 0:6:1, contrastando com maiores acúmulos ocorridos quando as plantas foram submetidas às soluções 4:2:1, 3:3:1, 1:5:1 e 6:0:1, como observado na Tabela 2. Os menores acúmulos podem ser atribuídos à ausência do cálcio, o que é confirmado pelo fato de os tratamentos nos quais se adicionou cálcio apresentarem maior acúmulo de magnésio, com exceção do tratamento com relação cálcio:potássio 5:1. Esse último provavelmente ocorreu devido à baixa disponibilidade do potássio nessa solução, pois a alta relação cálcio:potássio pode ter influenciado na absorção do magnésio, conforme também detectado por Silva et al. (1995) e Rodrigues e Rossiello (1995), trabalhando com espécies forrageiras.

Em pupunheira, foi constatado menor acúmulo de magnésio quando as mudas foram cultivadas na solução cuja relação cálcio:potássio foi $0: 6$, enquanto acúmulo superior ocorreu na solução com relação $3: 3$ (FERNANDES, 2000).

Semelhante ao magnésio, o acúmulo de enxofre foi reduzido quando as plantas foram cultivadas nas soluções contendo cálcio:potássio:sódio nas relações 5:1:1 e $0: 6: 1$, ao passo que, nas outras soluções, ocorreram os maiores valores acumulados, não havendo diferença significativa entre os tratamentos dentro desse grupo (Tabela 2). A redução verificada pode ser resultante do desbalanço entre os nutrientes cálcio e potássio.

Em relação ao sódio, percebe-se pela Tabela 2 que o açaizeiro comporta-se de forma independente quanto à presença ou não desse elemento na solução, pois não se verificou efeito na produção de matéria seca, embora tenha ocorrido redução no acúmulo de fósforo e magnésio nas mudas quando o sódio foi suprimido da solução.

\section{CONCLUSÕES}

De maneira geral, as soluções contendo cálcio, potássio e sódio nas relações 4:2:1 e 3:3:1 proporcionaram obtenção de mudas de açaizeiro com maior produção de matéria seca e maior acúmulo de nutrientes.

Mudas de açaizeiro não são afetadas pela presença do sódio no meio de cultivo. 


\section{REFERÊNCIAS BIBLIOGRÁFICAS}

ASSIS, R. P. de. Nutrição mineral e crescimento de mudas de dendezeiro (Elaeis guinensis Jacq.) em função de diferentes relações entre $K$, Ca e Mg na solução nutritiva. 1995. 41 f. Dissertação (Mestrado em Solos e Nutrição de Plantas) - Universidade Federal de Lavras, Lavras, 1995.

BONNEAU, X.; OCHS, R.; KITU, W. T.; YUSWOHADI. Chlorine: an essential element in the mineral nutrition of hybrid coconuts in Lampung (Indonesia). Oleagineux, Paris, v. 48, n. 4, p. 179-190, 1993.

CARMELO, Q. A. de C. Saturação por bases e relações entre K, Ca e Mg no solo na nutrição potássica do milho (Zea mays L.) cv. Piranão. 1989. 105 f. Tese (Doutorado em Solos e Nutrição de Plantas) - Escola Superior de Agricultura Luiz de Queiroz; Universidade de São Paulo, Piracicaba, 1989.

COSTACURTA, C. R. C.; VIÉGAS, I. de J. M.; SAMPAIO, M. do C. T.; CARVALHO, J. G. de. Produção de matéria seca e sua distribuição em diferentes partes da seringueira (Hevea brasiliensis Muel. Arg.) sob doses de cálcio. In: CONGRESSO BRASILEIRO DE CIÊNCIA DO SOLO, 25., 1995, Viçosa. Anais...Viçosa: SBCS, 1995. p. 1070-1072.

DALIPARTHY, J.; BARKER, A. V.; MONDAL, S. S. Potassium fractions with other nutrients in crops: a review focusing on the tropics. Journal of plant nutrition, New York, v. 17, n. 11, p. 1859-1886, 1994.

DUFOUR, F.; QUENCEZ, P.; SCHMITTY, G. Technique de culture en solutions nutritives du palmier a huile et du cocotier. Oléagineux, Paris, v. 33, n. 10, p. 485-490, Oct. 1978.

FERNANDES, A. R. Nutrição mineral e crescimento de mudas de pupunheira (Bactris gasipaes H. B. K.), em solução nutritiva, em função do balanço de nutrientes e níveis de salinidade. 2000. 145 p. Tese (Doutorado em Solos e Nutrição de Plantas) - Universidade Federal de Lavras, Lavras, 2000.

GUNES, A.; ALPASLAN, M.; INAL, A. Critical nutrient concentrations and antagonistic and synergistic relationships among the nutrients of NFT-grown young tomato plants. Journal of Plant Nutrition, New York, v. 21, n. 10 , p. 2035-2047, 1998.
KURIHARA, C. H. Nutrição mineral e crescimento da soja sob influência do equilíbrio entre $\mathrm{Ca}, \mathrm{Mg}$ e $\mathrm{K}$. 1991. 95 f. Dissertação (Mestrado em Solos e Nutrição de Plantas) - Universidade Federal de Lavras, Lavras, 1991.

MAGAT, S. S.; PADRONES, G. D.; ALFORJA, L. M. Residual effects of three chloride fertilizers on yeld and leaf nutrient levels of coconuts grown on inland soil of Davao (Mindanao, Philippines). Oleagineux, Paris, v. 48, p. 237-242, 1993.

MALAVOLTA, E. Manual de química agrícola. São Paulo: Agronômica Ceres, 1976. 528 p.

MARSCHNER, H. Mineral nutrition of higher plants. 2. ed. London: Academic, 1997. 889 p.

MENGEL, K.; KIRKBY, E. A. Principles of plant nutrition. 4. ed. Bern: International Potash Institute, 1987. $687 \mathrm{p}$.

MORTVEDET, J. J.; KHASAWNEH, F. E. Effects of growth response on cationic relationships in plants. Soil Science, Baltimore, v. 141, n. 3, p. 200-207, Mar. 1986.

OLIVEIRA, M. do S. P. de; LEMOS, M. A.; SANTOS, V. F. dos; SANTOS, E. O. dos. Correlações fenotípicas entre caracteres vegetativos e de produção de frutos em açaizeiro. Revista Brasileira de Fruticultura, Jaboticabal, v. 22, n. 1, p. 1-5, abr. 2000.

PACHECO, R. G.; SOUZA JÚNIOR, J. O. de; AGUILAR, M. A. G.; CARDOSO, A. A.; MARTINEZ, H. E. P.; OLIVEIRA, J. A. de. Efeitos de doses crescentes de potássio no crescimento inicial da pupunha (Bactris gasipes H. B.K.). In: CONGRESSO BRASILEIRO DE CIÊNCIA DO SOLO, 27., 1999, Brasília. Anais... Brasília: SBCS, 1999. CD-ROM.

RODRIGUES, A. C. da G.; ROSSIELLO, R. O. P. Crescimento, absorção de $\mathrm{K}, \mathrm{Ca}$, e $\mathrm{Mg}$ de forrageiras tropicais em função da adubação potássica. In: CONGRESSO BRASILEIRO DE CIÊNCIA DO SOLO, 25., 1995, Viçosa. Anais...Viçosa: SBCS, 1995. p. $1252-1254$.

SILVA, N. M. A.; SILVEIRA, R. I.; GOMIDE, C. A.; CARRER, R. C. O.; LIMA, C. G. de. Produção e composição de gramíneas forrageiras submetidas á níveis de potássio, cálcio e sódio. I-Capim-Andropogon cv. Planaltina. In: CONGRESSO BRASILEIRO DE CIÊNCIA DO SOLO, 25., 1995, Viçosa. Anais... Viçosa: SBCS, 1995. p. 10511053. 
SONNEVELD, C.; VOOGT, S. Growt and cation absorption of some fruit-vegetable crops grown on rockool as affected by different cation rations in the nutrient solution. Journal of Plant Nutrition, New York, v. 8, p. 585-602, 1985.

TAIZ, L.; ZEIGER, E. Plant physiology. Redwood City: The Benjamin/Cummings, 1991. 559 p.
VENTURA, C. A. D. Níveis de potássio, cálcio e magnésio em solução nutritiva influenciando o crescimento e a composição da soja (Glycine Max (L.) Merryl), cv. Paraná. 1987. 65 f. Tese (Doutorado em Solos e Nutrição de Plantas) - Escola Superior de Agricultura Luiz de Queiroz; Universidade de São Paulo, Piracicaba, 1987. 